\title{
El legado católico en la acumulación de riqueza y ahorro de un ecuatoriano
}

\section{The catholic legacy in the accumulation of wealth and savings of an ecuadorian}

Miguel Mauricio Cueva Estrada

Pontificia Universidad Católica Argentina, Argentina

Autor para correspondencia: miguel.cuevae@ug.edu.ec

Fecha de recepción: 04 de Diciembre 2017 - Fecha de aceptación: 15 de Junio de 2018

Resumen: Para Max Weber, el capitalismo era un hecho concluyente que determinaba el destino del hombre y era resultado de la interrelación de elementos económicos, religiosos, morales, éticos, entre otros. Este pensador explicó la concepción económica que lleva a la riqueza, como un imperativo moral, para esto, su pensamiento concebía a la religión como un aspecto de importancia e influencia para el desarrollo, llevando a los países protestantes a tener un mejor desempeño económico frente a países que profesaban la fe católica y veían el crédito como usura. La influencia del Catolicismo en la economía ecuatoriana está disminuyendo, pero por años, desde la llegada de los españoles, ha dejado una impronta que podría haber influido en los patrones de acumulación de riqueza y por ende en el ahorro de la población. Aparentemente existe una diferenciación en el comportamiento de los ahorristas de la región costa y sierra del Ecuador y parte de este comportamiento tendría explicación en la propensión religiosa que poseen los pueblos de estas regiones. Este trabajo busca explicar a la luz de la teoría que Max Weber presentada en su ensayo La ética protestante y el espíritu del capitalismo, las diferencias en los patrones de ahorro y las variables, no necesariamente de corte económico que inciden en él, soportado en argumentación teórica y data estadística que tienen como fuente organismo estales.

Palabras Claves: legado católico; riquezas; capitalismo

Abstract: For Max Weber, capitalism was a conclusive fact that determined the destiny of man and was the result of the interrelation of economic, religious, moral, ethical elements, among others. This thinker explained the economic conception that leads to wealth, as a moral imperative, for this, his thought conceived religion as an aspect of importance and influence for development, leading the Protestant countries to have a better economic performance in front of countries that professed the Catholic faith and saw credit as usury. The influence of Catholicism in the Ecuadorian economy is decreasing, but for years, since the arrival of the Spaniards, it has left an imprint that could have influenced the patterns of accumulation of wealth and therefore savings of the population. Apparently there is a differentiation in the behavior of savers in the coastal and mountain regions of Ecuador and part of this behavior could be explained by the religious propensity of the peoples of these regions. This work seeks to explain in the light of the theory that Max Weber presented in his essay The Protestant Ethic and the Spirit of Capitalism, the differences in saving patterns and variables, not necessarily of an economic cut that affect it, supported by argumentation Theoretical and statistical data that have stales as a source.

Key Words: catholic legacy; riches; capitalism 


\section{Introducción}

¿Está aún vigente la tesis de Maximiliam Weber que planteaba que la ética protestante y sus ideas puritanas influyen en el desarrollo del capitalismo? ; ¿Esta teoría podría explicar la diferencia en los patrones de acumulación de riqueza y por ende de ahorro en el Ecuador?; ¿Existen diferencias en estos patrones de ahorro y acumulación de riqueza entre costeños y serranos sustentados por esta teoría? El objetivo general que se pretende alcanzar con este trabajo es determinar si la incidencia católica y protestante, han influenciado en los patrones de acumulación de riqueza y ahorro en el comportamiento de costeños y serranos del Ecuador.

\section{Protestantismo y ascetismo}

La iglesia protestante, aquella corriente religiosa que sentó sus orígenes en la ideas de Martín Lutero, quién creía que la salvación no era por obras sino por fe, apoyaba una ética cristiana materialista, buscando la perfección moral y espiritual con un estilo de vida austero y de renuncia a los placeres materiales.

En este marco el ascetismo (figura 1) en su concepción más básica implica un estilo de vida austero y de renuncia a los placeres materiales, buscando practicar hábitos que lleven a un perfeccionamiento moral y espiritual. Pero desde la perspectiva calvinista, su forma de ver el ascetismo, "no implica el retiro o el aislamiento del mundo como forma de purificación y, por lo tanto, la renuncia a la vida práctica" (Pérez Franco, 2004, pág. 308), lo que se podría concebir como un ascetismo intramundano, tal cual lo denomina Pérez (2004).

Lo anterior tuvo incidencia en la concepción de una ética que ve al trabajo como un desarrollo ineludible de una vocación para alcanzar así la salvación eterna y que según Gil Villegas (2003), en palabras de Weber, se denominaba Visión del Mundo. La fuerza explicativa de esta idea radica en su relación con condiciones históricas materiales, especialmente económicas, relacionadas a intereses sociales. Estos intereses toman como propios los alcances del sentido ético del trabajo como una vocación (acumular y reinvertir), implicación de una forma particular de comportamiento en la vida, inserta en una dinámica económica, lo que aportó sumado a otros factores, al surgimiento de un espíritu que impulsó el desarrollo del capitalismo.

La interrelación mutua (Figura2) entre la "visión de mundo", la "conducción de vida" y los "múltiples intereses" constituyen el esquema central del estudio de Max Weber de la relación entre la ética protestante y el espíritu del capitalismo y en ningún momento su objetivo fue explicar el surgimiento del capitalismo como sistema económico, sino de rasgos ascéticos, austeros o sobrios en el pensamiento burgués; "para Weber no era suficiente una explicación únicamente motivacional, ni una exclusivamente institucional o material, de los procesos sociales, sino una fundada en la relación entre ambos factores" (Gil Villegas Montiel F. , 2003, pág. 29). (Figura3)

\section{Bosquejo de las ideas de Maximiliam Weber}

Dos muestras (artículos) del pensamiento de Maximiliam Weber, fueron publicados por la revista académica alemana de Ciencias Sociales Archiv für Sozialwissenschaft und Sozialpolitik, en los que se refirió a la relación existente entre la ética protestantes y el espíritu 
del capitalismo; estos trabajos fueron, reeditados por él y publicados posteriormente a su muerte en 1920.

\section{Tesis central de su obra}

Podría considerarse que la idea central de la obra La Ética protestante y el Espíritu del Capitalismo, era mostrar una relación existente entre los preceptos religiosos y la formación de las grandes unidades de producción en el occidente. Weber propone como tesis que la ética protestante y las ideas puritanas que surgieron alrededor de ella, influenciaron el desarrollo del capitalismo en el mundo. Fundamentaba su argumento en que la fe, la devoción y la inclinación religiosa, van de la mano al rechazo de hechos mundanos y dentro de ellos a la búsqueda de una mejor posición económica.

Para algunos, el planteamiento de Weber se reduce a una "supuesta explicación genética que la ética protestante tuvo en el desarrollo del capitalismo como sistema económico" (Pérez Franco, 2004, pág. 306). Para Pérez (2004) lo que planteó inicialmente Weber, no buscaba:

...mostrar la causalidad genética del capitalismo como sistema económico en la relación mecánica entre una creencia religiosa, como el ascetismo ${ }^{1}$ protestante, y el desarrollo de la conducta económica capitalista, misma que pudiera generalizarse a cualquier época u organización social. (pág. 306)

\section{Lo que realmente pensó Weber}

Para Pérez (2004) "Weber no escribió en ningún lugar que el surgimiento del capitalismo estuviera determinado unicausalmente por la ética protestante" (pág. 308). "En sus célebres ensayos sobre el protestantismo, Weber jamás tuvo la intención de explicar el surgimiento y desarrollo del capitalismo como fenómeno histórico y económico, y menos aún como sistema" (Pérez Franco, 2004, pág. 308).

Según Villegas citado por Pérez (2004), expresa que Weber con base en las investigaciones existentes sobre la relación de creencias religiosas y conducta económica, discute lo que se concebía como predestinación a ser elegidos o condenados según el protestantismo, con especial énfasis en el calvinismo y teniendo "como objetivo desarrollar un medio que permitiera a los creyentes borrar los signos de condena” (Pérez Franco, 2004, pág. 308).

Weber destacó el peculiar espíritu de empresa económica entre los primeros protestantes, caracterizado por la férrea disciplina, racionalidad y un elevado ascetismo, relacionado con complejas fuerzas que mediaban la acción financiera, que ha representado una poderosa influencia en el crecimiento de la civilización industrializada. (Behar, 2012, pág. 117)

\footnotetext{
${ }^{1}$ Ascetismo: 1. m. Hecho de profesar la vida ascética. 2. m. Doctrina de la vida ascética. 3. m. Cualidad de ascético. Proviene de asceta 1. m. y f. Persona que, en busca de la perfección espiritual, vive en la renuncia de lo mundano y en la disciplina de las exigencias del cuerpo.
} 
"El carácter protestante cultiva la disposición al servicio de los demás y al autocontrol constante, con prohibiciones de la sensualidad y espontaneidad, sentimiento de culpa y se orientan hacia la eficiencia y la obtención de logros" (Behar, 2012, pág. 118).

Weber en sus ideas originales no buscaba mostrar la causalidad genética del capitalismo como sistema económico en la relación en la mecánica entre una creencia religiosa, como el ascetismo protestante, y el desarrollo de la conducta económica capitalista, que pudiera generalizarse a cualquier época u organización social.

En ningún lugar expresa que el surgimiento del capitalismo estuviera determinado unicausalmente por la ética protestante; jamás tuvo la intención de explicar el surgimiento y desarrollo del capitalismo como fenómeno histórico y económico, y menos aún como sistema, haciéndolo en obras posteriores.

\section{Ecuador y sus diferencias regionales}

Ecuador, un país pequeño de 17 millones de habitantes, tiene su población concentrada en las grandes ciudades: Quito, Guayaquil y Cuenca. Se divide en cuatro regiones: costa, sierra, oriente e insular con diferencias en la disponibilidad de recursos naturales. Costa y sierra poseen zonas agrícolas relativamente desarrolladas, con una mezcla de producción dirigida a lo nacional y productos de calidad a exportación.

Entre sus ciudades más importantes resalta Guayaquil, fundada originalmente para facilitar el comercio de la capital Quito con el Reino de España, pero con el tiempo adquirió su propia fisionomía. Inicia su afirmación económica en el siglo XVIII con la producción de cacao, que impulso su crecimiento y fomentó la migración del campo a la ciudad. Con el paso del tiempo sigue su crecimiento con la industria del banano, química, plástico, electrodomésticos, camarón y exportaciones. Ganó importancia económica inclusive por encima de lo regional, lo que a su vez influyo sobre su cultura. Por otro lado está Quito, la ciudad capital y entre ambas existen marcadas diferencias en lo económico, cultural y lo político.

Entre las generalizaciones más pintorescas y cuestionables ciertos autores sugieren que el empresario guayaquileño sería más "audaz", listo para asumir riesgos, pero más "indisciplinado" que su homólogo quiteño. El guayaquileño sería "impulsivo, violento, orgulloso", mientras que el quiteño sería "tacaño, chismoso y traidor". En la política, el hombre de la Costa sería pragmático mientras que el de la Sierra más bien romántico e idealista. En cuanto a la religión, el uno sería incrédulo por ignorancia y el otro devoto por mimetismo. (Jimenez Sánchez, 1999).

Lo anterior es solo una pequeña muestra de las zanjadas diferencias entre poblaciones costeñas y serranas, diferencias que podrían proyectarse a la inclinación religiosa, motivando valores que inciden en la acumulación de riqueza y ahorro. 
Ecuador según el historiador Enrique Ayala Mora (2002), en su vida republicana ha enfrentado más de cien conflictos internos armados registrando miles de muertos, cifra superior inclusive a las bajas generadas por conflictos bélicos internacionales.

... en buena parte de estos conflictos armados internos los ecuatorianos se enfrentaban convencidos que defendían la causa de Dios o la de la libertad de conciencia. Por más de un siglo, el país estuvo dividido por la cuestión religiosa. El monopolio ideológico de la Iglesia Católica fue suprimido a inicios del siglo $\mathrm{XX}$, por la reforma liberal, que garantizó la libertad de pensamiento y religión. Pero el enfrentamiento se agudizó. Solo en las últimas décadas se ha logrado una vigencia efectiva del laicismo y la igualdad de creencias religiosas. Al mismo tiempo que se ha superado el enfrentamiento confesional, la sociedad ecuatoriana ha comenzado a aceptar las diferencias en ese aspecto. En nuestros días ya los ecuatorianos asumimos como una realidad el que haya en el país varias confesiones religiosas, o personas que no profesan religión alguna. También hemos asumido que el derecho fundamental al pensamiento libre tiene los más diversos niveles de ejercicio y aplicación. (Ayala Mora , 2002, pág. 11).

No es ilógico pensar entonces que el tinte religioso impregna muchas de las actividades de los ecuatorianos.

\section{El legado religioso español}

Los españoles conjuntamente a su legado de dolor, dejaron el catolicismo al colonizarnos. Esta doctrina no tuvo cuestionamientos por muchos siglos, influenciando y formando la consciencia social de la población ecuatoriana. El pensamiento religioso forma parte de los valores de nuestra sociedad, constituyendo por ende también un componente de nuestra cultura. Pero actualmente la fuerza del catolicismo en Ecuador se está reduciendo y por el contrario nuevas religiones como el cristianismo evangélico, testigos de Jehová, pentecostales, mormones entre otras han ganado terreno, esto seguramente puede haber incidido en el surgimiento de nuevos valores incluido lo económico.

Con el pasar del tiempo, los ecuatorianos han adoptado nuevos valores económicos que permiten el desarrollo y ahorro de capital, tales como el trabajo arduo, la libertad de poseer riqueza sin temor a los dogmas católicos de pobreza y obediencia, anhelar calidad de vida en este mundo y no solo después de la muerte, ganar recompensa espiritual en base a las buenas acciones cotidianas y no mediante la confesión sacerdotal. A la par, una cantidad cada vez mayor de católicos sufre una conversión a las iglesias protestantes, quienes poseen enseñanzas más flexibles en el ámbito financiero. (Bustamante Vergara , 2014)

\section{Las cifras hoy}

Es muy natural para los seres humanos, buscar soluciones o explicaciones divinas a las cosas que experimenta día a día, y generalmente explicar a través de la fe en un ser superior las cosas que no podemos entender, que por su complejidad no podemos resolver. Todas las 
religiones hacen referencias a seres superiores omnipotentes, omniscientes e incluso omnipresentes, que transmiten un mensaje que en su fiel cumplimiento asegura a quienes en ellos creen, gloria y salvación. Esto ha creado en el pensamiento de un sujeto expuesto a estas creencias, la convicción de que sus problemas serán resueltos por este o estos seres superiores.

Las bases expuestas de la teoría de Weber y las diferencias culturales nos hacen cuestionar si, ¿existe alguna relación entre el aumento de la riqueza de un sujeto y la religión? y si esto ¿establece una relación con el ahorro? y tratamos bosquejar de forma básica algún tipo de relación entre el ahorro que lleva a la acumulación de riqueza y la fe religiosa que un sujeto tiene.

Tomando como referencia, las Primeras Estadísticas oficiales sobre filiación Religiosa en el Ecuador (INEC, 2012), los ecuatorianos dentro de las cosas que son importantes para su vida, la religión apenas representa el 2,84\% de esas cosas importantes (Figura 4). Para las mujeres $(3,30 \%)$, es más impotente la religión en comparación con los hombres $(2,32 \%)$, en relación a otras cosas que consideran importantes, pero de igual forma la religión es una de las cosas importantes que menos les importan a los ecuatorianos (Figura5).

Afirman tener filiación religiosa el 91,95\%, ateos son 7,94\% y agnósticos 0,11\% (Figura 6). El 80,44\% de la población dicen profesar la fe católica (Figura 7). Para los ecuatorianos católicos la fe es una disposición que permite llegar a la salvación a través de la devoción y la puesta en práctica lo que dicen los curas en sus sermones. Para un ecuatoriano protestante, sus valores los motivan a incrementar su capital personal, sin que esta acumulación de capital tenga una tonalidad perniciosa; "Quienes se han beneficiado con el progreso de la nación, se han apartado de la religión ecuatoriana tradicional ya que perciben una falta de vínculo y empatía con ella y han encontrado afinidad en las doctrinas protestantes" (Bustamante Vergara , 2014).

La Iglesia Católica ha perdido fuerza al volverse su doctrina cada vez más incompatible con la realidad que viven los ecuatorianos. Sus preceptos de obediencia y humildad, se buscan imponer ante la acumulación de riqueza y capital, lo que incide en el ahorro que resulta del trabajo de una persona, las cuales desentonan con la concepción del devoto y que constituyen la motivación para cambiar a religiones más protestantes que les confieran no solo libertad de culto religioso, sino también de acción en su búsqueda de mejoramiento de sus condiciones.

Indiscutiblemente existen varias razones por las cuales un fiel católico opta por la conversión religiosa, tales como la satisfacción de la identidad, por ser una tendencia en auge, por eventos traumáticos y decepcionantes con su iglesia tradicional, entre otras emociones que describe William James en "The Varieties of Religious Experience" (James, 2014).

Al llegar a este punto, cabe preguntarse si los ecuatorianos abandonan la religión tradicional católica en búsqueda de nueva riquezas o la búsqueda de mejoramiento en sus condiciones económicas los ha llevado a mejoramientos en sus condiciones de vida y relaciones personales que los han encaminado a experimentar otras realidades inclusive nuevas religiones.

Con estos hechos en mente podemos descifrar certeramente que la respuesta a la inquietud planteada desde el inicio sobre los motivos para el incremento de la conversión religiosa, es la identidad que brinda cada religión a sus seguidores a 
través de sus catequizas. Son estas premisas las que han influenciado la conversión de católicos creyentes a cristianos protestantes fervientes. La metodología con la que imparten sus fundamentos resulta atrayente porque es empática con las emociones de las personas y en su mayoría promueven sentimientos profundos con esparcimiento y alegría, asentando así a la religión como fuente de identidad a la par. (Bustamante Vergara , 2014, págs. 15-16)

Posiblemente los ecuatorianos estamos abandonando poco a poco la costumbre católica de nuestros padres para mutar a una creencia religiosa por convicción o conveniencia y quizás uno de los principales sustentos en este cambio de comportamiento se deba a que las nuevas generaciones poseen mayor riqueza comparada con los anteriores, esto podría justificar porqué actualmente hijos de familias católicas profesen otra religión.

Las clases bajas se mantienen atadas al tradicional catolicismo y al sistema de hacienda. De esta manera, el protestantismo también se convierte en una forma de revolución contra el status quo religioso, el monopolio de la fe, y la estructura social establecida por la iglesia (Betrán, 2010, pág. 75).

Según la Encuesta Nacional de Ingresos y Gastos (ENIGHUR) 2011- 2012, el ingreso total promedio mensual por hogar en el área urbana es de USD 1.046,3; mientras en el área rural es de 567,1 dólares (Figura 8). El 58,8\% de los hogares tiene capacidad de ahorro, mientras el $41,1 \%$ de hogares tiene mayores gastos que ingresos (Figura 9). Posiblemente en Ecuador las cosas no están ocurriendo como lo ha propuesto la tesis de Weber al relacionar la religión y la riqueza. Seguramente en Ecuador el producto del mejoramiento de sus condiciones económicas, el incremento de sus centros industriales y la industrialización de su producción, la movilidad económica y social de las personas y los recursos, se constituyen en causas que impactan la vida de las personas podrían estar influenciando su conversión religiosa y por ende afectando los patrones de acumulación de riqueza y ahorro, implicando libertad y autonomía en las acciones emprendidas en relación a la religión.

La incidencia de misioneros en su mayoría de origen estadounidense, cautiva inicialmente a la población indígena que constituye el $7 \%$ de la población ecuatoriana actualmente, pero con el paso de los años alcanza a todas las clases sociales, con un discurso que habla de mejores tiempos y da esperanza ante la pobreza, el desempleo y los tiempos difíciles. Posiblemente todo comenzó con un grupo de católicos que no encajaban en las doctrinas de la iglesia y buscaban una alternativa de fe, que aportara a su interés personal y sentimiento de libertad, incluido el aspecto económico.

¿Qué relación tiene esto con el ahorro? Primero delimitémoslo. Las personas ahorran dinero como un mecanismo de defensa para reducir su fragilidad ante eventos externos negativos que los puedan afectar. "Con ahorros, en especie o en efectivo, se crea una red de seguridad" (Dauner Guardiol, 2004). "El ahorro define la acción de apartar una parte del ingreso corriente para consumirlo o invertirlo en un futuro" (Dauner Guardiol, 2004). El ahorro en forma monetaria es solamente un modo de gestionar la liquidez del hogar. Si el crédito está disponible, también es usado para la gestión de liquidez. Las acciones de ahorrar y des ahorrar (consumir más que el ingreso corriente), de prestar dinero y solicitar un préstamo, interactúan 
constantemente. Las causas por las que ahorran las personas son: disminución de la vulnerabilidad, acumular sumas importantes, legado a parientes y amigos y obtención o pago de un crédito. El promedio de ahorro de la costa durante el año 2007 y la sierra expresa diferencia (Figura 10), aun cuando la serie de datos es muy corta, se puede notar una marcada diferencia en el promedio de ahorro por cuenta. Un ahorrista promedio en la sierra durante el último año ha tenido en promedio entre USD 900 y USD 1200 en su cuenta. Para un ahorrista de la costa, el promedio osciló entre USD 700 y USD 800. Los datos no son concluyentes para afirmar si costeños o serranos ahorran más en función a sus creencias religiosas pero si nos dan la idea que el ahorro en Ecuador alcanza niveles muy bajos.

\section{Conclusiones}

Nos cuestionamos sobre las verdaderas razones por las cuales los creyentes ecuatorianos han migrado de una fe católica a religiones protestantes. Para Maximilliam Weber la migración de una fe católica a religiones protestantes ha llevado a la acumulación de riquezas en países que se apropiaron de esta fe protestante.

En el Ecuador en función de lo encontrado en la revisión bibliográfica de este trabajo, se puede expresar que a pesar de que la población ecuatoriana tiene aún una marcada raíz católica, las nuevas generaciones la están abandonando. No se ha encontrado en este estudio argumentos suficientes para poder decir que la propuesta teórica de weber en su relación fe - riqueza, explique completamente el deseo de cambio de religión en las nuevas generaciones.

Surge entonces la duda si en el Ecuador está ocurriendo lo contrario, es decir que el mejoramiento económico es el que está llevando a una migración de la fe religiosa. Una de la causa de estos cambio de fe religiosa se podría explicar, cómo lo expresa William Beltrán por el incremento de misiones religiosa provenientes de los Estados Unidos, fenómeno similar ocurrido por toda América del Sur. (Betrán, 2010). Estas misiones incidieron en la propagación de valores como individualización del creyente, mayor autonomía, participación religiosa, incidiendo esto en el mejoramiento de sus condiciones económicas.

\section{Bibliografía}

Ayala Mora, E. (2002). Ecuador: Patria De Todos La nación ecuatoriana, unidad en la diversidad. Quito: Universidad Andina Simón Bolívar.

Behar, R. (2012). Espiritualidad y ascetismo en la anorexia nerviosa. REV CHIL NEUROPSIQUIAT, 117-129.

Betrán, W. (2010). Ensayo parte de los documentos preliminares de la tesis doctoral "Pluralisation religieuse et changement social en Colombie". Paris Francias: niversité de la Sorbonne .

Bustamante Vergara, F. D. (Marzo de 2014). La conversión religiosa del catolicismo al protestantismo como resultado del incremento de capital en los ecuatorianos. La conversión religiosa del catolicismo al protestantismo como resultado del incremento de capital en los ecuatorianos. Quito, Pichincha, Ecuador: Universidad san Francisco de Quito. 
Dauner Guardiol, I. (2004). Movilización del Ahorro. Temas claves y buenas prácticas en la promoción del ahorro. Cosude Agencia Suiza Para El Desarrollo Y La Cooperación.

Ecuatoriano, E. (s.f.). Nueva historia del Ecaudor (Vol. 15).

Fiebig Michael (2001), Prudential Regulation and Supervision for Agricultural Finance, FAO, AFR, GTZ, Italy.

Gil Villegas Montiel , F. (2003). Notas Críticas, en La etica protestante y espíritu del capitalismo. México: Fondo de Cultura Económica.

Gil Villegas Montiel, F. (2003). Introducción del Editos, en La Ética protestante y el espíritu del capitalimso . México: Fondo de Cultura Económcia .

INEC. (Agosto de 2012). Primeras estadísticas oficiales sobre filiación religiosa en el Ecuador. Primeras estadísticas oficiales sobre filiación religiosa en el Ecuador. Ecuador: Instituto Nacional De Estad’Siticas Y Censos Del Ecuador.

James, W. (7 de marzo de 2014). eBooks@ Adelaide. Obtenido de The University of Adelaide Library: http://ebooks.adelaide.edu.au/j/james/william/varieties/

Jimenez Sánchez, F. (1999). Conflictos regionales y poder central en los países andinos: los casos de ayacucho en Perú y Guayaquil ene Ecuador. Guayaquil, Gauayquil, Ecuador: Universidad de Especialidades Espíritu Santo.

Pérez Franco, M. (2004). La ética protestante y el espíritu del capitalismo / Max Weber ; introducción y edición crítica de Francisco Gil Villegas M. Sociológica, 19(55), 303-316.

Robinson Marguerite (2002), The Microfinance Revolution. Volume 2: Lessons from Indonesia. World Bank, Washington DC.

Saavedra Dahm, O. (s.f.). Análisis de la obra: La ética protestante y el espíritu del capitalismo de Max Weber. 87 - 95. 


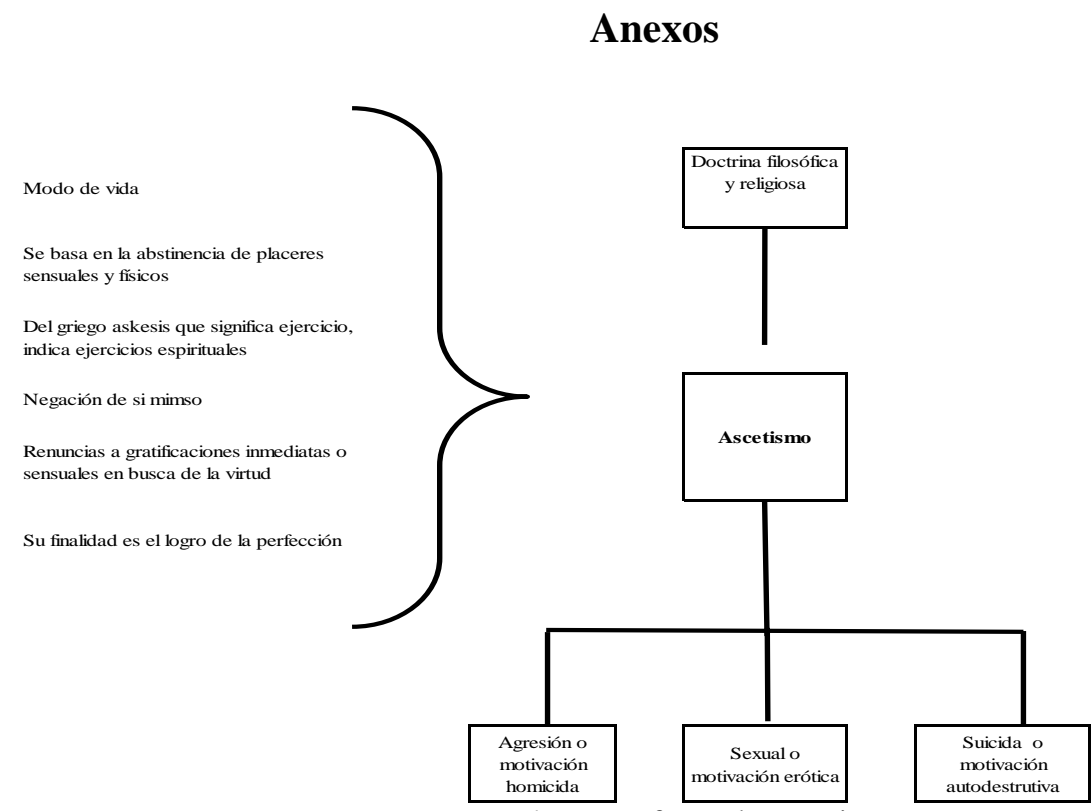

Figura 1: Mentefacto de ascetismo.

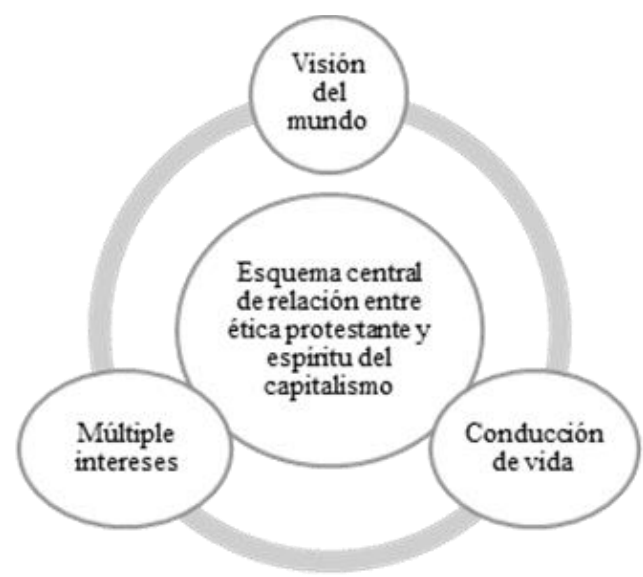

Figura 2: Esquema central de relación entre ética protestantes y espíritu de capitalismo. 


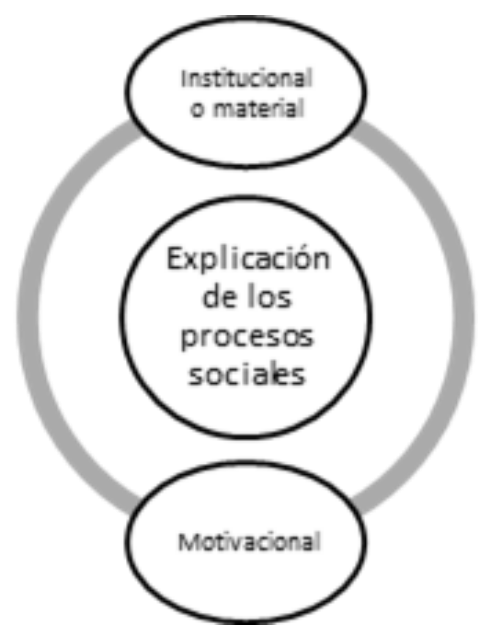

Figura 3: Procesos sociales según Weber

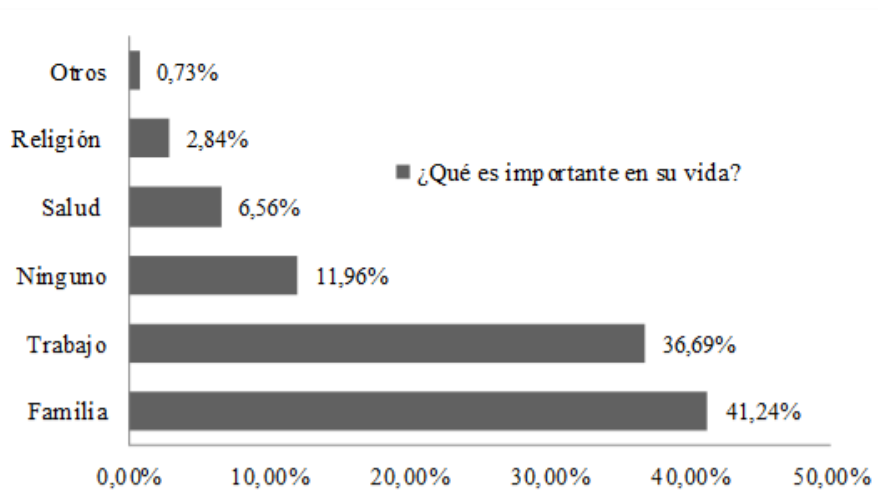

Figura 4: Cosas más importantes para los ecuatorianos.

Fuente: Sistema integrado de encuestas de hogares - INEC

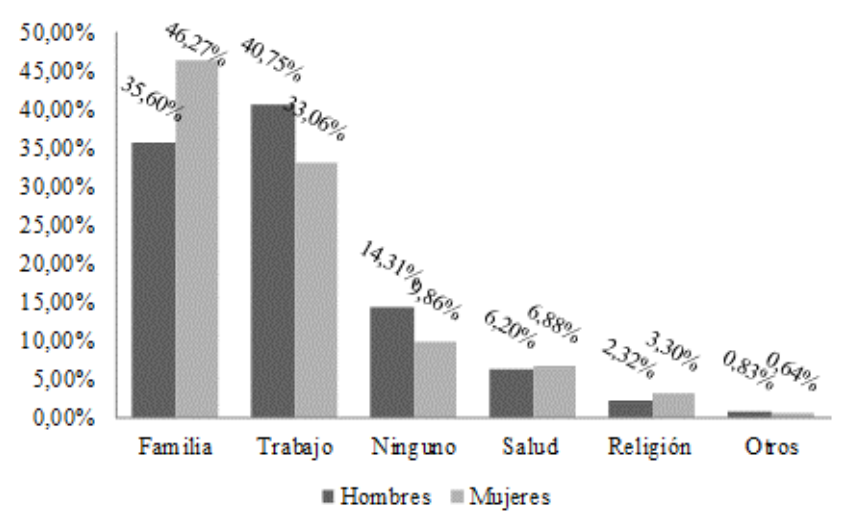

Figura 5: Cosas más importantes para los ecuatorianos, según su sexo.

Fuente: Sistema integrado de encuestas de hogares - INEC 


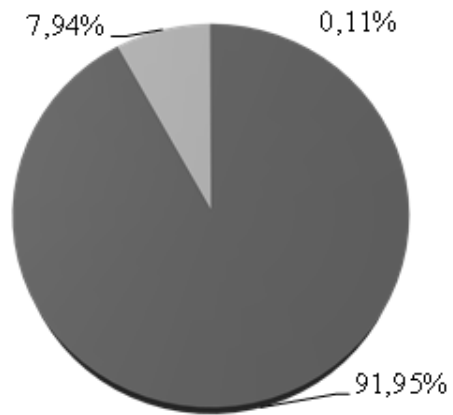

- Afirman tener una religión Ateos Agnóstico

Figura 6: Filiación religiosa.

Fuente: Sistema integrado de encuestas de hogares - INEC

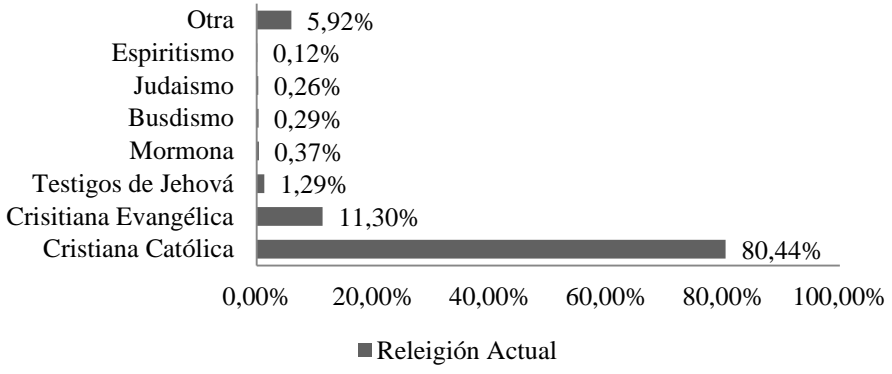

Figura 7: Filiación religiosa.

Fuente: Sistema integrado de encuestas de hogares - INEC

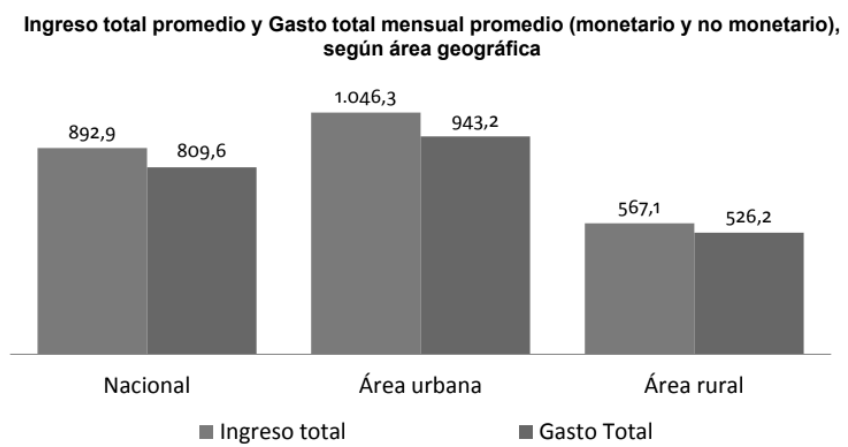

Figura 8: Ingreso vs. Gasto en hogares ecuatorianos. Fuente: Sistema integrado de encuestas de hogares - INEC 
Porcentaje de hogares según ingresos totales vs. Gastos totales*

\begin{tabular}{l|r|r|}
\hline \multicolumn{1}{|c|}{ Categorias } & Hogares & $\%$ \\
\hline $\begin{array}{l}\text { Hogares con ingresos mayores } \\
\text { a los gastos }\end{array}$ & 2.307 .991 & 58,8 \\
$\begin{array}{l}\text { Hogares con gastos mayores } \\
\text { a los ingresos }\end{array}$ & 1.613 .011 & 41,1 \\
\hline $\begin{array}{l}\text { Hogares con ingresos iguales a } \\
\text { los gastos }\end{array}$ & 2.121 & 0,1 \\
\hline \begin{tabular}{l} 
Total \\
\hline
\end{tabular} & $\mathbf{3 . 9 2 3 . 1 2 3}$ & $\mathbf{1 0 0 , 0}$ \\
\hline
\end{tabular}

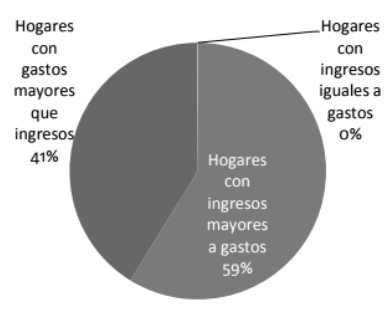

*Incluye ingresos y gastos monetarios y no monetarios

Figura 9: Capacidad de ahorro en hogares ecuatorianos.

Fuente: Sistema integrado de encuestas de hogares - INEC

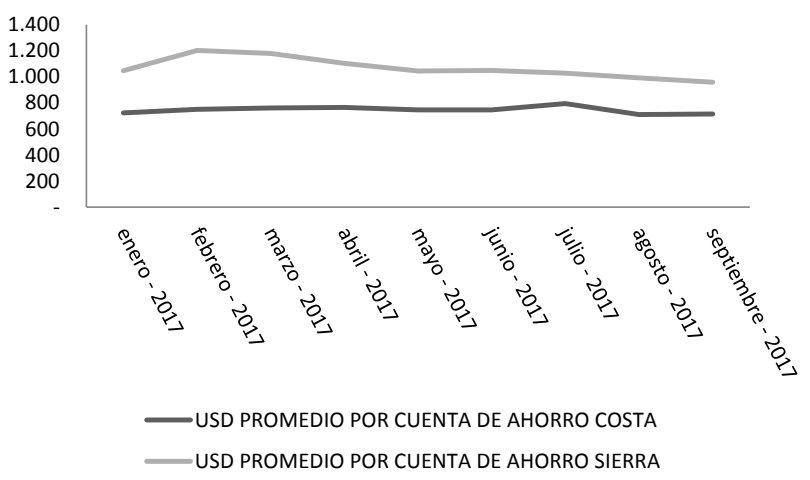

Figura 10: Ahorro promedio por cuenta en costa y sierra Fuente: Superintendencia de Bancos 